\title{
O REGISTRO CIVIL DAS PESSOAS NATURAIS: INSTRUMENTO DO BIOPODER E DE AUXÍLIO AO PLANEJAMENTO URBANO
}

\author{
Jefferson Aparecido Dias* \\ Olavo Figueiredo Cardoso Jr. *
}

\section{RESUMO}

O presente trabalho se dedicou a analisar o Registro Civil das Pessoas Naturais (RCPN) como instrumento de biopoder em prol de um melhor planejamento urbano. A relevância do presente estudo está no fato de o RCPN, além de fundamental à sociedade para segurança e estabilidade das relações jurídicas, também ter a potencialidade de servir para um melhor planejamento urbano e eficiência do Estado, em especial a partir de sua concepção como um importante mecanismo de controle decorrente do biopoder, o que foi possível de se observar a partir de uma pesquisa documental, de natureza analítico-descritiva e de cunho exploratório.

Palavras-chaves: Registro civil. Biopoder. Planejamento Urbano. Gestão Pública. Eficiência do Estado.

\section{THE CIVIL REGISTRY OF NATURAL PERSONS: AN INSTRUMENT OF BIOPOWER AND SUPPORT TO URBAN PLANNING}

\begin{abstract}
The aim of this work was devoted to analyze the Civil Registry of Natural Persons (RCPN, an acronym in Portuguese) as a instrument for biopower in favor of better urban planning. The relevance of the present study lies in the fact that the RCPN, in addition to being fundamental to society for security and stability of legal relations, also has the potential to serve for better urban planning and State efficiency, especially from its conception as a important mechanism of control resulting from biopower, which was possible to observe from a documentary research, of analytical-descriptive nature and exploratory nature.
\end{abstract}

Keywords: Civil registry; Biopower; Urban planning; Public administration; Efficiency of the State

\section{INTRODUÇÃO}

O biopoder é pertinente tanto a pesquisas na área de saúde pública, controle de riscos sanitários e genéticos, quanto a estudos em comunicação. É constituído a partir da ordenação

\footnotetext{
* Doutor em Direitos Humanos e Desenvolvimento pela Universidad Pablo de Olavide, Sevilha, Espanha. Procurador da República em Marília (SP). Professor da Graduação, do Mestrado e do Doutorado em Direito da UNIMAR (Universidade de Marília). Av. Higino Muzi Filho, 1001 - Câmpus Universitário - Jardim Araxa, Marília - SP, 17525-902. E-mail: jeffersondias@unimar.br.

** Mestre em Direito pela Escola Paulista de Direito de São Paulo e Mestre em Direito pela UNIMAR (Universidade de Marília). Doutorando em Direito pela UNIMAR (Universidade de Marília). Atualmente é $2 \square$ Tabelião de Notas e de Protesto de Títulos na Comarca de Marília-SP. Avenida Rio Branco, 04 - Centro, Marília - SP, 17500090. E-mail: protestonotas@gmail.com.
} 
de regiões espaciais (geográficas) através do bioespaço, por meio de um método que emprega linguagem similar a dos ecossistemas.

Nesse sentido, pode-se dizer que o biopoder tem como foco a população, tanto para proporcionar fecundidade, bem-estar e segurança, quanto para controlar e, na medida do possível, reduzir as enfermidades ou as mortalidades, mesmo quando controla comportamentos individuais.

O biopoder, na regulação da população, passa a ser, de forma eminente, uma técnica política que opera por meio das diversas entidades institucionais e estatais incumbidas de manter a gestão sobre a vida.

Com respeito ao Registro Civil de Pessoas Naturais (RCPN), este poderia ser definido como aquele previsto nas Leis 6015/73 e 8.935/94, objetivando fixar, com fé pública, os principais fatos e atos relativos às pessoas naturais.

Assim, justifica-se o presente trabalho pelo fato do RCPN poder vir a ser uma ferramenta poderosa de biopoder, já que o Estado pode empregá-la como instrumento de planejamento público, tornando-se ainda mais eficaz na medida que há um intenso interesse estatal sobre a seara dos registros públicos, em particular sobre o RCPN, sob o "pretexto" de garantir acesso à cidadania, a qual, sob o manto da cláusula pétrea do art. $5^{\circ}$, inciso LXXII, da Constituição Federal, prevê a gratuidade a diversos tipos de atos obrigatórios, cujas informações são repassadas ao Estado.

A problemática ora em questão traduz-se em questionar que tipo de dados e de informações são carreadas ao Estado pelo Registro Civil de Pessoas Naturais, e como este, enquanto instrumento de biopoder e munido desse todo esse acervo, pode trabalhar a serviço de um melhor planejamento urbano.

Neste sentido, a metodologia empregada para o desenvolvimento do presente estudo foi uma pesquisa documental, de natureza analítico-descritiva e de cunho exploratório.

\section{BIOPODER}

A biorrevolução, segundo Silva (2006), vem consagrar a superação da partilha e da disputa por território, enquanto organização mundial do capital e forma de domínio, de modo a introduzir, mediante o bioespaço, um novo tipo de geopolítica. Tendendo a organizar a nova 
ordem global nos anos que se seguirão, o biopoder constitui-se a partir da ordenação das regiões do planeta por meio do bioespaço, conforme um método que utiliza a mesma linguagem dos ecossistemas, e aparece como privilégio e propriedade exclusivamente pertencente às grandes empresas e aos órgãos estatais.

A expressão biopoder, recorrente nas obras comentadas de Michel Foucault, é decorrente do conceito de biopolítica, referente à atividade dos Estados modernos direcionada ao controle dos assujeitados, mediante diversos dispositivos e técnicas que buscam submeter, por meio da coerção institucional, corpos humanos e seus produtos. Tal poder, com o disciplinamento das expressões humanas que envolvam o corpo, organiza-se em um tipo de política anatômica corpórea. A palavra biopoder é pertinente tanto a pesquisas na área de saúde pública, controle de riscos sanitários e genéticos, quanto a estudos em comunicação (RAGO, 2008).

Conforme aponta Alves (2004), historicamente, pode-se dizer que o poder disciplinar, a começar pela segunda metade do século XVIII, passa a incorporar o biopoder, complementando-o, já que não ocorre uma efetiva substituição de um pelo outro, mas um aperfeiçoamento. Isto é, o biopoder se instala no poder disciplinar, embutindo e integrando a disciplina, modificando-a conforme os propósitos estatais. Segundo Foucault (1999), o biopoder não elimina a disciplina porque pertence a outro domínio, possuí outra base de suporte e é ajudado por instrumentos completamente distintos. Portanto, os dois tipos de poder passam a coabitar o mesmo espaço e tempo.

Por conseguinte, de acordo com Candiotto (2010), o biopoder distribuí o poder disciplinar de forma diferente, sem eliminá-lo. O poder disciplinar, que surge no século XVII, é praticado sobre o homem-corpo. Por outro lado, o biopoder, do século XVIII, tem o homemespécie como foco. Enquanto que a disciplina dos corpos opera o instrumento de sujeição de forma a tornar os corpos úteis e dóceis, o biopoder, investido contra a população, passa a controla-la por meio da biopolítica das regulações.

É preciso elucidar que o poder disciplinar não é constituído por uma negatividade, ele não tenciona expiar uma falta ou um crime realizado, muito menos reprimir, ele visa produzir uma positividade nas pessoas que são atravessadas por ele. Já a violência, por outro lado, ocorre como uma ação de repressão, frequentemente sufocante e em grande parte das 
vezes paralisante. Devido a isso, pode-se afirmar que a violência contém um aspecto negativo (RAGO, 2008).

Por conseguinte, Rago (2008) diz que o biopoder está associado à biopolítica. O francês Michael Foucault chamou de biopoder o poder que, surgido no fim do século XVII e início do século XVIII, passou a atuar na vida dos indivíduos, estabelecendo uma população em uma multidão mais ou menos ordenada, igual a um novo corpo, que deixa de ser individualizado e passa a ser coletivo. Combinado com o biopoder, o poder disciplinar se fundamenta, de forma necessária, em saberes, tais como higienistas, médicos, demográficos e estatísticos, por exemplo. No entanto, distintamente do poder disciplinar, quase que um requisito para seu surgimento, o biopoder visa a população, tanto para proporcionar fecundidade, bem-estar e segurança quanto para controlar e, na medida do possível, reduzir as enfermidades, as mortalidades etc., mesmo quando governa comportamento individuais. Assim, a inversão sugerida por Foucault se deu a partir dessa articulação entre o biopoder e o poder disciplinar. Tal inversão é o principal atributo da Modernidade, onde o "deixar viver fazer morrer" é suplantando pelo "fazer viver - deixar morrer".

Segundo Branco e Veiga Neto (2011), consiste na normalização da multiplicidade, pois, se sobre os corpos age a disciplina para fazê-los aptos, produtivos e adaptados às diversas atividades sociais, o biopoder, na regulação da população, passa a ser, de forma eminente, uma técnica política que opera por meio das diversas entidades institucionais e estatais incumbidas de manter a vida sob gestão.

Adotando essa perspectiva, Fonseca (2011) esclarece que, se anteriormente ao século XIX notava-se de forma separada as disciplinas de sujeitação corpórea às escolhas, aos exércitos e às disciplinas de controle demográfico, mediante expectativas de vida e a tabulações de riquezas, depois desse momento, agenciamentos concretos, que conjugarão os meios estratégicos de assujeitamento da espécie e do corpo, passam a articular a grande tecnologia do biopoder. De acordo com Foucault, um dos dispositivos mais importantes desse agenciamento é a sexualidade, de forma que seu estudo é fundamental para que se aprenda o conceito de biopoder e de seus impactos na constituição do homem moderno.

Continuando nessa linha de raciocínio e com respeito à sexualidade, Fonseca (2011) explica que, esta, enquanto correlatado da scientia sexualis, consiste na produção histórica que oportunizou a ligação do sexo às micropráticas do biopoder. Foi a única dimensão da vida 
que possibilitou um ajustamento tão favorável a esses mecanismos da política. O sexo encontra-se na zona de cruzamento entre os dois eixos fundamentais em torno dos quais o biopoder se estabeleceu, pois que oportuniza a ação sobre o corpo social e o corpo individual, já que impacta atos sutis, como o pensamento e o desejo, assim como os comportamentos coletivos mais genéricos dos cidadãos. Por isso, o biopoder tem acesso à vida, tanto da espécie como do corpo.

Devido a esse fato, vale destacar o porquê da problematização da conduta sexual ou do domínio do sexo feitos por Foucault. Nessa esfera, estão duas tecnologias de poder: o biopoder e as disciplinas. É possível até dizer que ele problematizou o biopoder enquanto desdobramento do estudo do dispositivo sexual. Apenas mais tarde Foucault pesou o biopoder por meio da perspectiva da guerra entre raças, conforme indica o nome do curso por ele ministrado: Il faut défendre la sociéte, de 1997 (BRANCO; VEIGA-NETO, 2011).

Não é apenas para disciplinar os comportamentos individuais que o biopoder age sobre o sexo, mas é, especialmente, para regular e gerenciar a vida dos indivíduos em sua totalidade. Compreende-se, portanto, a razão da conjugação entre sexualidades marginas, como a sexualidade infantil, e a disciplina e o biopoder. Na primeira, a ação do poder se deu devido a demandas de regulação, no entanto, conquistou resultado semelhante ao das disciplinas. Em se tratando da regulação, tinha-se em mente que controlando a sexualidade dos menores se poderia controlar a sexualidade dos adultos e, consequentemente, as forças vitais e a vontade para a realização do trabalho produtivo. Porém, o resultado dessa regulação é de caráter disciplinar, não seria possível furtar-se a uma sociedade viciada em prazer mediante a regulação se as esferas de disciplina da escola e da família não atentassem para o corpo do infante, para seus gestos mais insignificantes, a partir de uma organização nova dos espaços e do gerenciamento do tempo de suas práticas (BRANCO; VEIGA-NETO, 2011).

As variações são inúmeras, mas podem ser vistas entre ambas as mecânicas de poder em voga. À medida que o poder disciplinar age sobre os corpos das pessoas, o biopoder dirige suas vidas. Ao mesmo tempo que a disciplina faz com que os homens se tornem individuais, o biopoder promove a massificação, considerando que ele se volta para a população. Por isso que as consequências do biopoder podem ser sentidas sempre global, coletiva e conjuntamente, e são processos que constituem a vida dos cidadãos, como, por exemplo, o ato de nascer, de adoecer e de morrer. O biopoder ocupa-se precisamente desses processos de 
mortalidade, longevidade e natalidade, tanto relacionando o número de morte e de nascimento como averiguando o índice de fecundidade de um corpo social. Ou seja, os exemplos dados por Foucault para elucidar esse tipo de poder são variados (ALVES, 2004).

O biopoder, de forma diferente do poder disciplinar, é direcionado para o conjunto dos indivíduos, não conforme eles se sintetizem em corpos, mas conforme eles componham uma massa global perturbada por processos de conjunto que estão presentes na vida, como a doença, a produção, a morte, o nascimento etc. (FOUCAULT, 1997).

Assim, segundo Candiotto (2010), o objeto do biopoder é a massa global, ou seja, a população. Por assim dizer, o âmbito dos corpos particularizados, enquanto objeto de atuação do poder disciplinar, é expandido para o espaço da população, onde age o biopoder. De fato, com exceção da ênfase no minucioso controle dos corpos em uma massiva regulação da vida do outro, os dois objetos de poder constituem multiplicidades de totalização e de individualização.

É fundamental notar que, nesses processos em que o biopoder é exercido, existe uma produção concomitantemente ampla de conhecimento, envolvendo as ciências biológicas e exatas. Especialmente os saberes da Biologia e a Estatística passam a ser de extrema importância na fase em que são necessárias soluções para doenças, políticas de natalidade, demografias etc. A higiene pública torna-se a principal questão da Medicina e, assim, pode-se concluir que o biopoder adota uma forma de poder de polícia, conforme contemporaneamente compreende-se esse tipo de poder. Novas instituições e novos mecanismos, como a poupança e a seguridade social, são promovidos pelo biopoder (FOUCAULT, 1999).

Além disso, têm sido denominados de conflitos de territorialidades os atos reativos ao biopoder. É um conflito que se funda nas fronteiras do não capitalismo e do capitalismo, e que passam a se reinventar nas bordas do biopoder, seja mediante a integração do seu tradicional saber ao saber de ponto, o conhecimento de engenharia em progresso e daquele que, na estratégia do tempo, é dependente, seja mediante a expansão do capital rentista em busca de absorver os excedentes trabalhistas até o momento isentados desses modelos sociais não-proletários (SILVA; LIMA; CORREIA, 2006).

De certo modo, Lukács antevê esses conflitos quanto teoriza as sociabilidades, mesmo que no domínio de desenvolvimento de uma ontologia de base marxista. Lukács, leitor de Rosa Luxemburgo, meio que prevê esse "retomo ao futuro" do capitalismo de trazer 
o bioespaço para a era da terceira revolução industrial, enquanto uma forma de organização técnica das escalas de espaço, confrontando o não capitalismo e o capitalismo para rearranjar as relações de reciprocidade deste para com aquele, tanto para patentear seu saberes para o lucro imediato e privado do capital rentista quanto para utilizar o conhecimento biotecnológico tradicional do não capitalismo para fazer progredir, o mais rapidamente possível, o saber biotecnológico da modernidade (SILVA; LIMA; CORREIA, 2006).

Sibilia (2002) destaca que a introjeção e a intervenção nos corpos, cada vez mais recorrente, gera efeitos que superam sua toxidade, previsível ou conhecida, em potencial. Isto é, as possíveis consequências da utilização de biotecnológicos ultrapassam os riscos à saúde dos indivíduos, já que, ao estabelecerem trocas mais íntimas e fluidas com o organismo, anulam mais ainda os limites entre o artificial e o natural. Compreendido, no momento, como um poder que faz viver, que torna a vida coletiva humana mais longa mediante sofisticados argumentos e técnicas biológicas, o biopoder está mais do que nunca exposto. Assim, ao se dizer que a seleção natural é superada pelo progresso tecnológico em eficiência e rapidez, o biopoder vem a ser aquilo que pode, a princípio, libertar-nos das restrições e das contingências do acaso no destino da nossa espécie, já que o biopoder, intermediado pela biologia, não apenas faz viver, mas assegura fazê-lo de forma mais eficiente que as leis naturais.

\section{O REGISTRO CIVIL DAS PESSOAS NATURAIS COMO INSTRUMENTO DE BIOPODER}

Neste capítulo, vamos procurar mostrar como o Registro Civil das Pessoas Naturais (RCPN), no Brasil, tornou-se uma poderosa ferramenta de biopoder, e passou a ser empregado pelo Estado como instrumento de dominação, realidade essa que se aprofunda dia a dia.

Inicialmente o Registro Civil era paroquial e ficava a cargo da igreja católica. Mas logo começou a enfrentar problemas face à entrada de imigrantes e de professantes de outras religiões, que a ele não se subordinavam. Em paralelo, conduta análoga era praticada pelos escravos libertos, adeptos de religiões africanas (SANTOS, 2006, p. 15-16). Nesse diapasão, o Estado estava perdendo o controle de importantes dados demográficos diante de um sistema de Registro Civil lacunoso, o qual não alcançava a nova dinâmica populacional que se 
avizinhava. Era necessário secularizar o sistema para que o controle fosse mantido sobre os dados populacionais. Desta forma, o registro de nascimento, casamento e óbito de pessoas não católicas passou a ser feito por Escrivães dos Juízos de Paz, com apoio na Lei 1.144, de 11 de setembro de 1861, seguida pelo Regulamento 3.069, de 17 de abril de 1863. Posteriormente, editou-se a Lei 1.829 , de 09 de setembro de 1870 , cujo artigo $2^{\circ}$ foi regulado pelo Decreto 5.604, de 1874. Mais tarde, novo Regulamento foi feito, por meio do Decreto 9.886, de 7 de março de 1888 , com entrada em vigor em $1^{\circ}$ de janeiro de 1889 . Este é o histórico legislativo inicial pelo qual o Registro Civil, no Brasil, migrou das hostes paroquiais católicas e passou a ser lavrado em livros próprios, por escrivães do Juizado de Paz, em cada Freguesia do Império. A ideia era alcançar, gradativamente, toda a população da época, independentemente da cor ou da religião do registrando (SANTOS, 2006, p. 15-16). Esse novo registro constituíase em importante meio de prova, com o qual se demonstrava o nascimento, a idade, o nome e a filiação das pessoas naturais, assim como o estado civil (incluindo o casamento celebrado por autoridades religiosas), e os óbitos,

Em 15 de novembro de 1889, com o advento da Proclamação da República, o Brasil se tornou laico o casamento civil através do registro da solenidade do ato, na forma do Decreto 181 de 1890 e, atualmente, pelo Código Civil Brasileiro, no artigo 1.536.

No dia $1^{\circ}$ de janeiro de 1916, foi promulgado o Código Civil Brasileiro, cuja autoria foi de Clovis Bevilácqua, entrando em vigor após um ano, em $1^{\circ}$ de janeiro de 1917. Em seguida, temos uma série de diplomas legais tratando de registros públicos, a saber (ARPENSP, 2017):

1- Lei 4.827, de 07 de fevereiro de 1924;

2- Decreto 18.542, de 24 de dezembro de 1928;

3- Decreto 4.857 de 09 de novembro de 1939, alterado posteriormente pelos;

4- Decreto 5.318, de 29 de fevereiro de 1940, que somente altera dispositivos do Decreto 4.857;

5- Decreto 13.556, de 30 de setembro de 1943, que também altera alguns dispositivos do Decreto 4.857/39;

6- Decreto-Lei 1.000, de 21 de outubro de 1.969, que revogou a Lei 4.827/24 e o Decreto 4.587/1939;

7- Lei 6015/73, lei vigente atualmente, com posteriores alterações. 
Difícil não é perceber, à luz da farta legislação sobre a matéria, o intenso interesse estatal sobre a seara dos registros públicos, em particular sobre o registro concernente às pessoas físicas ou naturais. A ressalva é importante para deixar claro que, sob o guarda-chuva dos registros públicos, não estão abrigados somente os atos concernentes às pessoas naturais. Eles abarcam, também, o registro de títulos e documentos, o registro de imóveis, o registro civil de pessoas jurídicas, além de diversos outros registros especiais, como marcas e patentes, direitos autorais, aeronaves e embarcações, para ficarmos apenas nesses, os quais refogem o restrito objeto de estudo aqui tratado.

Em apertada síntese, poderíamos tentar definir o RCPN como aquele previsto nas Leis $6015 / 73$ e $8.935 / 94$, destinado a fixar, com fé pública, os principais fatos e atos relativos às pessoas naturais.

Segue a didática definição de Mário de Carvalho de Camargo Neto e Marcelo Salorali de Oliveira, com apoio no artigo $1^{\circ}$, da Lei 8.935/94:

O Registro Civil de Pessoas Naturais é serviço público de organização técnica e administrativa destinado a garantir publicidade, autenticidade, segurança e eficácia dos atos e fatos da vida, bem como do estado da pessoa natural (CAMARGO NETO, 2014, p. 17).

Esse serviço é exercido por particulares, selecionados por concurso público de títulos e provas, por força do comando constitucional constante do artigo 236, da Lei Maior. Tais particulares, nos termos do art. $3^{\circ}$ da Lei 8.935/94, são profissionais do direito, a quem o estado outorga fé pública para a prática desses atos.

A Lei 8.935/94, no seu artigo $4^{\circ}$, determina que os serviços sejam prestados de "forma eficiente e adequada". Inexiste liberdade de escolha quanto ao dia e hora que os mesmos devam funcionar, pois eles são determinados pelo juízo competente, em regra o corregedor local. A Lei 6.015/73, artigo $8^{\circ}$, parágrafo único, determina que devam funcionar todos os dias. Em São Paulo é observado um sistema de plantão quanto a isso. Devem, ainda, ter acessibilidade fácil ao público e possuir instalações revestidas de segurança, a fim de permitir o arquivamento dos livros e documentos do serviço.

É imensa a capilaridade do RCPN, fato pouco notado pelos estudiosos. Na totalidade dos municípios, sem importar sua dimensão ou número de habitantes, existe ao menos um RCPN em funcionamento. Caso o município tenha grande extensão territorial, a juízo do 
respectivo Estado, em cada sede distrital poderá funcionar também, no mínimo, um serviço de Registro Civil das pessoas naturais (BRASIL, 1994).

É notável o detalhamento legal do Registro Civil, o que confere enorme segurança e confiabilidade ao teor de cada assento. Os atos são praticados em livros próprios, cada um para uma finalidade legalmente prevista. Destarte tem-se, segundo o art. 33, da Lei 6.015/73:

Art. 33. Haverá, em cada cartório, os seguintes livros, todos com 300
(trezentas) folhas cada um (Redação dada pela Lei no 6.216 , de 1974):
I - "A" - de registro de nascimento;
II - "B" - de registro de casamento;
III - "B Auxiliar" - de registro de casamento Religioso para Efeitos Civis;
IV - "C" - de registro de óbitos;
V - "C Auxiliar" - de registro de natimortos;
VI - "D" - de registro de proclama.
Parágrafo único. No cartório do $1^{\circ}$ Ofício ou da $1^{a}$ subdivisão judiciária, em
cada comarca, haverá outro livro para inscrição dos demais atos relativos ao
estado civil, designado sob a letra "E", com cento e cinqüenta folhas,
podendo o juiz competente, nas comarcas de grande movimento, autorizar o
seu desdobramento, pela natureza dos atos que nele devam ser registrados,
em livros especiais.

A cada um dos livros mencionados acima deverá ser juntado um índice em ordem alfabética dos assentos neles lavrados, formado a partir do nome das pessoas participantes dos atos, para permitir a realização de buscas rápidas e precisas.

Por questões de confiabilidade e segurança dos dados constantes dos registros, há enormes restrições para suas alterações. A retificação somente é livre no momento do ato, antes da assinatura das partes, ou logo em seguida, antes da lavratura do próximo assento, com nova coleta de assinatura de todas as partes envolvidas (BRASIL, 1973, art. 40). As emendas e alterações que não observem esse procedimento são consideradas inexistentes, não gerando qualquer efeito jurídico (BRASIL, 1973, art. 41). Desta forma, os assentos só podem ser alterados de acordo com os procedimentos previstos da Lei de Registros Públicos, nos artigos 109 e 110 (este último com redação dada pela Lei no 13.484, de 2017), os quais impõe manifestação judicial ou do Ministério Público, exceto para os casos de pouca indagação, como erros ostensivos de grafia, ou inexatidões na transposição de dados documentais, por exemplo. Nos demais casos, portanto, a contrário sensu, é obrigatória a intervenção do estadojuiz, com instauração de processo judicial, ou de manifestação do Ministério Público. 
Existe enorme interesse estatal para imprimir máxima eficiência e alcance ao Registro Civil. Nesse sentido, embora o mencionado comando constitucional contido no artigo 236 da Constituição Federal determine que devam funcionar em caráter privado, sem prejuízo da natureza pública desses serviços, o Estado tem concedido uma série de gratuidades, de modo a conferir total efetividade na manutenção e atualização dos dados e informações populacionais ali registrados. Destarte, foi promulgada a Lei 9.534/97, alterando o art. 30, da Lei de Registro Públicos, estipulando a gratuidade dos atos de registro de nascimento e de óbito, e a primeira certidão daí decorrente.

Ressalve-se que tal gratuidade é concedida independentemente da situação econômica do interessado, o que demonstra com clareza solar o interesse do governo na formação e atualização desses dados, sob o argumento que eles são indispensáveis ao exercício da cidadania, na forma da Lei 9.265/96 igualmente alterada pela Lei 9.534/97, no tocante à gratuidade. Não se discorda que tais serviços sejam indispensáveis à concretude do macro princípio da cidadania, constante da Lei Maior, no art. $1^{\circ}$, inciso II. Eles de fato o são, pois é característica dos usos e costumes pátrios a exigência de prova documentada para efetividade jurídica de praticamente todos os direitos, mesmo quando assim a lei não o exija. Entender as razões desse traço da cultura brasileira exigiria uma profunda investigação, cujas respostas certamente exigiriam um mergulho histórico na formação brasileira, no bojo de um estudo que transcenderia o direito positivo. Mas sem prejuízo do apego à formalidade existente no Brasil, é preciso tentar compreender as razões de fundo do interesse estatal nos dados e informações constantes do RCPN, afora sua indispensabilidade para o exercício da cidadania.

Destarte, a própria Constituição Federal, no seu artigo $5^{\circ}$, inciso LXXII, carrega a previsão de gratuidade para os atos necessários ao exercício da cidadania, a qual encontra-se revestida com o manto da cláusula pétrea, até mesmo em razão da sua topografia no texto da Lei Maior.

As iniciativas de fortalecimento do controle populacional, já desde o nascimento da pessoa humana, receberam um grande reforço, emanado do Conselho Nacional de Justiça (CNJ). Com efeito, em 2009, pela via do Provimento 03/09, o órgão de controle do Poder Judiciário simplificou e padronizou as certidões de nascimento, casamento e óbito, criando um modelo nacional, com a introdução de um número de matrícula único, obrigatório desde 
2010. O mesmo órgão, através do Provimento 13/2010, regulamentou os procedimentos necessários para emissão de certidão de nascimento, antes que a criança saia da maternidade.

A Lei 11.790/08 e o Provimento 28/2013, do CNJ são outras iniciativas, tomadas recentemente, no sentido de procurar cercar, de todas as formas, a população de controles estatais no momento do nascimento, tornando mais fácil o acesso ao registro a qualquer momento. A Lei 11.790/08, alterando o art. 46 da Lei de Registros Públicos, começou a permitir a declaração de nascimento, não importando a idade do registrando, necessitando para tanto apenas a presença de duas testemunhas ao ato, sem previsão de nenhuma penalidade.

Em 2015, o CNJ publicou o Provimento 46/2015, pelo qual foi criada a Central de Informações de Registro Civil das Pessoas Naturais - CRC. Esse organismo foi uma elevação, em escala nacional, de centrais que já funcionavam em nível estadual e eram mantidas pelas respectivas associações de registradores locais, que funcionavam com autorização das Corregedorias Gerais da Justiça dos Estados de Minas Gerais, Paraná, Rio de Janeiro, Rio Grande do Sul, Santa Catarina e São Paulo. O objetivo da CRC, como consta claramente do seu artigo $1^{\mathrm{o}}$ e incisos, é formar um sistema interligado, disponibilizado na rede mundial de computadores, para, dentre outras metas: interligar os oficiais de Registro Civil; permitir o intercâmbio de documentos eletrônicos; o tráfego de informações e dados; possibilitar a implantação em âmbito nacional de um sistema de localização de dados e de emissão de certidões; possibilitar ao Poder Pública poder acessar de forma direta às informações constantes do Registro Civil; e a interligação com o Ministério das Relações Exteriores e repartições consulares a fim de obtenção de dados da vida civil relativos a brasileiros que estejam no exterior.

Outro controle estatal conectado ao RCPN, recentemente criado pela Instrução Normativa da Receita Federal do Brasil 1548/2015, art. 3º, V, foi a inscrição do recémnascido no Cadastro de Pessoa Física (CPF). Antes facultativo, e restrito a São Paulo e ao Rio de Janeiro, a emissão de CPF juntamente com a $1^{\mathrm{a}}$ certidão do registro de nascimento passou a ser obrigatória em todo o Brasil, nos termos do mencionado ato, e já supera a marca de um milhão de novos cadastros (G1 ECONOMIA, 2016).

Toda essa massa de dados e informações de nada adiantaria caso ficasse enclausurada nas unidades de Registro Civil. Destarte, a legislação e a normativa de regência no Estado de 
São Paulo, por exemplo, impõe a cada registrador o dever de enviá-los a um conjunto de órgãos públicos, conforme consta do Provimento 58/89 - Normas de Serviço, Tomo II, da Corregedoria da Justiça o Estado de São Paulo Capítulo XVII, itens 26, 27 e subitens, (SÃO PAULO, 1989).

1) à Secretaria Municipal de Saúde, a primeira via das Declarações de Nascido Vivo (DN) e de Óbito (DO), nos casos de parto ou morte natural sem assistência médica, observando, no que for possível, as edições do Ministério da Saúde relativas ao Manual de Preenchimento das Declarações de Nascido Vivo e de Óbito;

2) à Fundação SEADE, os dados para levantamento do número de nascimentos, casamentos, óbitos e natimortos, até o dia 10 do mês subsequente, assim como cópia das Declarações de Nascido Vivo (DN) e dos Atestados de Óbito (DO), até a regularização do registro perante o banco de dados da mesma Fundação;

3) à Fundação Nacional do Índio - FUNAI, o registro de nascimento de criança indígena, cujo comunicado deverá ser feito de imediato;

4) à Circunscrição de Recrutamento Militar correspondente ao respectivo distrito, em relatório mensal, os óbitos de brasileiro de sexo masculino, entre 17 e 45 anos de idade;

5) à Secretaria da Fazenda, mensalmente, relação dos óbitos registrados, com os dados da existência ou não de bens deixados pelo falecido;

6) a qualquer um dos Cartórios Eleitorais existentes na localidade em que estiverem situados os Registros Civis das Pessoas Naturais, relação dos óbitos dos cidadãos alistáveis, ocorridos no mês anterior, para cancelamento das inscrições, até o dia 15 de cada mês;

7) à Receita Federal do Brasil e ao Instituto Nacional do Seguro Social - INSS, mensalmente, até o dia 10 do mês subsequente, por meio eletrônico, a relação de óbitos registrados, independentemente da idade dos falecidos;

8) ao Ministério da Justiça, mensalmente, cópias dos registros de casamento e de óbito de estrangeiros;

9) ao Instituto de Identificação Ricardo Gumbleton Daunt - IIRGD e à Secretaria de Segurança Pública do Estado de São Paulo, até o dia 10 do mês subsequente, 
através da Central de Informações do Registro Civil - CRC, os dados de todos os óbitos Registrados no mês anterior;

10) à Central de Informações do Registro Civil (ARPEN-SP), em até dez dias da realização do ato, as informações referentes aos registros.

Recentemente, a Lei 13.444/17 (BRASIL, 2017) criou a Identificação Civil Nacional (ICN) e, em seu artigo $1^{\circ}$, objetiva fazer a identificação do brasileiro com respeito à suas relações com os órgãos e entidades privadas e governamentais bem como com a sociedade. Essa identificação tomará por base os dados biométricos, que estão sendo coligidos pela Justiça Eleitoral, a base de dados do Sistema Nacional de Informações de Registro Civil (Sirc), instituído através do Poder Executivo federal e da Central Nacional de Informações do Registro Civil (CRC Nacional), órgãos instituídos através do CNJ, observando o artigo 41 da Lei $n^{0} 11.977 / 09$, assim como outras informações, não contidas no Sirc, mas existentes nas bases de dados da Justiça Eleitoral, bem como dos institutos de identificação dos Estados e do Distrito Federal ou do Instituto Nacional de Identificação, ou disponibilizadas por outros órgãos, conforme definido pelo Comitê Gestor da ICN (Lei 1.444/17, art. 2º I, II e III).

Estabelece, ainda, o art. $2^{\circ}$, parágrafo $1^{\circ}$, Lei 13.444/17, que o armazenamento e o gerenciamento de toda essa base de dados ficarão sob a responsabilidade da Justiça Eleitoral.

\section{O RCPN E O PLANEJAMENTO URBANO}

A falta de acesso a informações de qualidade compromete a eficácia das regulamentações territoriais, pois constitui um obstáculo para obtenção de uma visão mais clara da dinâmica urbana sobre a qual se deseja influir. Além do mais, a imprecisão quanto a essa dinâmica urbana dificulta o exercício das diretrizes de inclusão socioespacial constantes na legislação brasileira.

Diversos municípios foram forçados a repensar seu plano diretor afim de adequá-lo às diretrizes nacionais, decorrentes das alterações promovidas na política urbana brasileira pelo Estatuto da Cidade, Lei 10.257/2001. Contudo, segundo a literatura, há certas dificuldades comuns nesse processo, como a falta de divulgação dos mecanismos de controle e de participação social e a falta de uma estrutura administrava apropriada para a execução do planejamento urbano (SANTOS JUNIOR; MONTANDON, 2011). Tais fatores, associados a 
nossa cultura política que dedica pouca importância ao planejamento e mira constantemente obter vantagens eleitorais em quaisquer iniciativas (SOUZA, 2004; CAMPOS FILHO, 1999), explicariam a baixa efetividade dos dispositivos municipais de planejamento urbano de hoje. Outro fator importante, e muitas vezes não mencionado pelos estudiosos do assunto, é a falta de acesso a informações territoriais capazes de expressar, com precisão, a dinâmica da apropriação do território urbano (FREITAS; GOMES; BORGES, 2013), problema que, em parte, poderia ser resolvido com o uso dos dados fornecidos pelo RCPN, os quais, nessa realidade, seriam importantes ferramentas a serviço do biopoder.

Segundo Matuda (2009), constam, nos recenseamentos do Registro Civil, dados dos fatos vitais sucedidos do país, resumindo a totalidade dos registros de óbitos fetais, óbitos e nascidos vivos. Fornecidas pelo RCPN, tem-se informações sobre as uniões matrimoniais e ainda sobre divórcios e separações judiciais proferidos pelas Varas Cíveis, Varas de Família ou Foros.

Dessa forma, tal instrumento pode ser uma valorosa fonte de dados demográficos uteis para a realização de estudos e de análises para o desenvolvimento de políticas públicas, servindo de suporte para a compreensão do cenário social. Conforme Magalhães (2015), inicialmente, o domínio dessas fontes demanda o entendimento da natureza dos dados, isto é, se são de estoque ou de fluxo. E, em segundo lugar, é necessário aprender a lidar com questões como: problemas de enumeração, cobertura territorial, regularidade, disponibilidade, dentre outras.

De acordo com Magalhães (2015), considerando que o Censo Demográfico oferece dados temáticos a respeito da população, indicando a composição e o seu tamanho, conforme diferentes critérios, o Registro Civil, por sua vez, é a fonte principal de informações dinâmicas, quer dizer, de informações derivadas de fatos que mudam a composição e o tamanho da população. Dito de outra forma, ao passo que o indivíduo, com todas as suas particularidades demográficas, econômicas e sociais, é a unidade de enumeração do Censo, o fato demográfico é a unidade do Registro Civil. O sistema de Registro Civil, assistindo de perto tais acontecimento (nupcialidade, migrações, óbitos, nascimentos, etc), oferece as designadas "estatísticas civis", as quais dispõem de certas características básicas, tais como: são veiculadas conforme local de ocorrência e de registro do fato; são colhidas e 
sistematizadas dia a dia, no decorrer do ano; e são resultantes de informações comunicadas e registradas em cartório de Registro Civil.

O Registro Civil, no Brasil, fornece dados para três sistemas extremamente relevantes para o estudo da sociedade e para a elaboração de políticas públicas, são eles o Sistema de Informações Hospitalares (SIH), cujos dados provêm da Autorização de Internação Hospitalar; o Sistema de Informações sobre Mortalidade (SIM), com dados resultantes da Declaração de Óbito; e o Sistema de Informações sobre Nascidos Vivos (SINASC), cujos dados advêm da Declaração de Nascido Vivo. Tais informações ficam concentradas no sítio eletrônico do DATASUS, que é o banco de dados do SUS de estatísticas vitais (OJIMA, 2012).

Conforme Nogueira e Sanson (2007), igualmente ao que se verifica nas capitais de maior número de habitantes, a falta de controle do crescimento populacional e a falta de planejamento urbano sistemático podem ser a origem de muitos problemas ambientais. A excessiva concentração de população em territórios específicos da cidade pode intensificar problemas como de carência de saneamento básico, poluição de águas, devastação da cobertura vegetal e apropriação desordenada no solo.

Sendo um exemplo mundial de como usar dados demográficos, em muitas regiões dos Estados Unidos, pensando na relação direta entre o crescimento da superfície impermeabilizada e o crescimento populacional, têm sido desenvolvidos cenários demográficos e de utilização de solo que encenam tendências e mostram o que, possivelmente, irá ocorrer nos próximos dez anos, resultando, dessa forma, em novas alternativas de ocupações com impactos menores (CONWAY; LOTHROPET, 2005). Conforme sublinham Cheng e Masser (2003), muitos estudos sobre expansão urbana têm empregado técnicas estatísticas de regressão linear em conjunto com um sistema de informação geográfica e com o sensoriamento remoto.

Os autores López et al. (2001) cruzaram a quantidade numérica de habitantes com a extensão territorial encobrida por superfície impermeabilizada, informação obtida a partir de fotografia aéreas do município de Morelia (México). Tal análise resultou em um modelo matemático que foi empregado para prever futuras impermeabilizações da superfície estudada. O exemplo ilustra apenas a potencialidade das informações que poderiam ser conseguidas com o RCPN, de maneira rápida e prática, exigindo, contudo, que esses dados 
sejam devidamente analisados para que fundamentem planejamentos urbanísticos mais eficientes e coerentes com as necessidades reais dos cidadãos.

Levando-se em consideração que, conforme constatado em 2008, a maioria da população mundial vive em centros urbanos, isso se torna significativamente importante (TUCCI, 2008). Temos, hoje, que mais de $84 \%$ dos brasileiros reside em perímetros urbanos (IBGE, 2010). Tal percentual é maior que $96 \%$ em cidades de estados mais desenvolvidos (SEADE, 2010), revelando taxas alarmantes de crescimento urbano e de urbanização.

É válido mencionar um exemplo brasileiro de utilização dos dados do RCPN para o embasamento de pesquisas referentes à mortalidade no Estado de São Paulo. De acordo com Maia, Cardoso e Silva (2016), comumente, os estudos sobre mortalidade contemplam os diferenciais geográficos, porém o registro de endereços disponibilizado pelo Registro Civil viabiliza um trabalho mais detalhado, de forma que permite detectar o endereço dos acontecimentos em qualquer unidade geográfica que se pretenda dar enfoque. Assim, com o emprego dos dados de mortalidade da SEADE, os quais, em 2001, foram georreferenciados por cada logradouro das cidades do Estado de São Paulo, com o que se obteve índices de mortalidade por agressões nas favelas e em suas redondezas, levando alguns estudos à conclusão, com dados objetivos, de que a violência no interior das favelas é mais grave do que em seu exterior.

Por conseguinte, com os dados provenientes do entrelaçamento das informações do Registro Civil, que representam importante mecanismo de controle do biopoder, a administração pública pode obter planejamentos urbanos mais efetivos na resolução e na diminuição dos problemas identificados em uma certa localidade, garantindo uma aplicação mais correta dos recursos públicos e um retorno mais satisfatório para a população como um todo.

Ademais, verifica-se nos municípios brasileiros de grande e médio porte, graves problemas ambientais, tanto no perímetro periurbano quanto no urbano. Muitas dessas cidades mostram uma tendência de urbanização fragmentada e dispersa, o que ocasiona uma densidade demográfica baixa e um extensivo e rápido consumo de recursos naturais, infraestrutura e território (LACERDA, 2005).

Portanto, a eficácia das decisões de planejamento depende de informações capazes de retratar, o mais precisamente possível, a realidade social. Considerando que a maioria das 
ações advindas da gestão e do planejamento urbano têm um importante componente espacial, o mapeamento das informações é de fundamental relevância, uma vez que possibilita uma melhor percepção, por partes dos órgãos de gestão urbana, do ambiente em que pretendem intervir.

\section{CONCLUSÃO}

Informação é poder. Sem informação é impossível governar e manter o poder.

Poucos estudiosos dão a devida atenção às serventias extrajudiciais previstas no artigo 236, da Constituição Federal. Conhecidas popularmente pela expressão "cartório", esses serviços, públicos na sua essência, com execução delegada a particulares selecionados em concurso, tornaram-se nas últimas décadas sentinelas avançadas do Estado, com obrigação legal de remeter a inúmeros órgãos estatais uma miríade de dados e informações, os quais seriam impossíveis de serem coletados de outra forma. Tais dados e informações, ao mesmo tempo em que são fundamentais à sociedade e às pessoas, enquanto sujeitos de direitos, com o fito de fornecer segurança e estabilidade às relações jurídicas, servem também de instrumento para o biopoder, pois subsidiam decisões que podem ser direcionadas tantos para finalidades políticas, como para outras, onde há legítimo interesse da população, como o planejamento urbano.

No que se referem aos registros civis de pessoas naturais, as informações revelam uma radiografia dinâmica da pessoa humana, acompanhando-a desde o nascimento até o óbito, informando, entre outras coisas, a localidade em que ela foi enterrada, o motivo de sua morte e se deixou bens ou ascendentes ou descendentes. Dificilmente haverá uma expressão de biopoder mais positivada e clara dos que os RPCN.

No Brasil, os dados fornecidos pelo Registro Civil são instrumentos importantes para a implementação de políticas públicas, para o monitoramento da prática da cidadania e para o acompanhamento do crescimento populacional. Porém, o Registro Civil, diferentemente dos censos, que, desde o princípio, tiveram seu gerenciamento atribuído a uma entidade estatal, ficou por muito tempo sem ser submetido a uma administração centralizada. Essa realidade, porém, mudou com o advento da Central de Registro Civil, inicialmente restrita a alguns 
estados, mas nacionalizada por meio da atuação do $\mathrm{CNJ}$, com a edição do Provimento $46 / 2005$

Contudo, é dever da administração pública buscar alternativas para apurar e para usar esses dados, de maneira mais eficiente, no desempenho da gestão pública, já que somente assim os recursos poderão ser melhor aplicados e a população brasileira melhor atendida no que, de fato, tem necessidade.

\section{REFERÊNCIAS}

ALVES, José Augusto Lindgreen. Nacionalismo e choque de etnias nos bálcãs. São Paulo: Lua Nova: Revista de Cultura e política. n. 63, 2004.

ARPEN-SP O Registro Civil no Brasil. Disponível em:

$<\mathrm{http}$ ://www.arpensp.org.br/index.cfm?pagina_id=177>. Acesso em: 20 julho 2017.

BRANCO, Guilherme Castelo; VEIGA-NETO, Alfredo. Foucault: filosofia \& política. Belo Horizonte: Autêntica, 2011. (Coleção Estudos Foucaultianos)

BRASIL. Conselho Nacional de Justiça. Corregedoria. Provimento $n^{0} 13$. Dispõe sobre a emissão de certidão de nascimento nos estabelecimentos de saúde que realizam parto. Diário oficial da união. Brasília 03 de set. 2010.

Conselho Nacional de Justiça. Corregedoria. Provimento n 28. Dispões sobre o registro tardio de nascimento, por oficial de registro civil das pessoas naturais, nas hipóteses que disciplina. Diário oficial da união. Brasília 05 fev. 2013.

Conselho Nacional de Justiça. Corregedoria. Provimento ${ }^{\circ}$ 46. Revoga o Provimento 38 de 25/07/2014 e dispõe sobre a Central de Informações de Registro Civil das Pessoas Naturais - CRC. Diário oficial da união. Brasília 16 jun. 2015.

. Constituição da república federativa do Brasil de 1988. Emendas constitucionais de revisão. Diário oficial da união. Brasília, 5 out. 1988.

Instrução normativa RFB no 1548 , de 13 de fevereiro de 2015. Dispõe sobre o Cadastro de Pessoas Físicas (CPF). Diário oficial da união. Brasília 19 fev. 2015, seção 1, p. 10 .

. Lei $\mathrm{n}^{\circ}$ 6.015, de 31 de dezembro de 1973. Dispõe sobre os registros públicos, e dá outras providências. Diário oficial da união. Brasília, 31 dez. 1973. 
. Lei no 8.935, de 18 de novembro de 1994. Mensagem de veto Regulamenta o art. 236 da Constituição Federal, dispondo sobre serviços notariais e de registro. (Lei dos cartórios) Diário oficial da união. Brasília 18 nov. 1994.

. Lei no 9.265, de 12 de fevereiro de 1996. Regulamenta o inciso LXXVII do art. $5^{\circ}$ da Constituição, dispondo sobre a gratuidade dos atos necessários ao exercício da cidadania. Diário oficial da união. Brasília, 12 fev. 1996.

Lei $\mathrm{n}^{\circ} 11.790$, de 2 de outubro de 2008. Altera o art. 46 da Lei no 6.015, de 31 de dezembro de 1973. Lei de Registros Públicos, para permitir o registro da declaração de nascimento fora do prazo legal diretamente nas serventias extrajudiciais, e dá outras providências. Diário oficial da união. Brasília 03 out. 2008.

. Lei n ${ }^{\circ} 11.977$, de 7 de julho de 2009. Dispõe sobre o Programa Minha Casa, Minha Vida - PMCMV e a regularização fundiária de assentamentos localizados em áreas urbanas; altera o Decreto-Lei no 3.365, de 21 de junho de 1941, as Leis nos 4.380, de 21 de agosto de 1964, 6.015, de 31 de dezembro de 1973, 8.036, de 11 de maio de 1990, e 10.257, de 10 de julho de 2001, e a Medida Provisória no 2.197-43, de 24 de agosto de 2001; e dá outras providências. Diário oficial da união. Brasília 7 jul. 2009.

. Lei $\mathrm{n}^{\circ} 13.444$, de 11 de maio de 2017. Dispõe sobre a Identificação Civil Nacional (ICN). Diário oficial da união. Brasília, 11 maio 2017.

. Lei $\mathrm{n}^{\mathrm{0}} 13.484$, de 26 de setembro de 2017. Altera a Lei $\mathrm{n}^{\circ} 6.015$, de 31 de dezembro de 1973, que dispõe sobre os registros públicos. Diário oficial da união. Brasília, 17 set. 2017.

CAMARGO NETO, Mario de Carvalho. Registro civil das pessoas naturais: parte geral e registro de Nascimento. São Paulo: Saraiva, 2014.

CANDIOTTO, Cesar. Foucault e a crítica da verdade. Belo Horizonte: Autêntica; Curitiba: Champagnat, 2010.

CHENG, J.; MASSER, I. Urban growth pattern modeling: a case study of Wuhan city, PR China. Landscape and Urban Planning, v. 62, p. 199-217, 2003.

CONWAY, T. M.; LATHROPET, R. G. Alternative land use regulations and environmental impacts: assessing future land use in an urbanizing watershed. Landscape and Urban Planning, v. 71, p. 1-15, 2005.

FONSECA, Márcio Alves da. Michel Foucault e a constituição do sujeito. 3. ed. São Paulo: EDUC, 2011.

FOUCAULT, Michel. Em defesa da sociedade. São Paulo: Martins Fontes, 1999. 
História da sexualidade I: a vontade de saber. Tradução de Maria Thereza Costa Albuquerque e J.A. Guilhon Albuquerque. Rio de Janeiro: Graal, 1988.

Resumo dos cursos do Collège de France: 1970-1982. Tradução de Andrea Daher. Rio de Janeiro: J. Zahar, 1997.

. A verdade e as formas jurídicas. São Paulo: Martins Fontes, 2005.

FREITAS, Clarissa; GOMES, Viridiana Gabriel; BORGES, Marcos. Planejamento urbano com uso de sistema de informação geográfica: o caso de Feira de Santana, BA. Universitas: Arquitetura e Comunicação Social, v. 10, n. 1, 2013.

G1 ECONOMIA. CPFs emitidos junto com certidão de nascimento superam 1 milhão. 31 out. 2016. Brasília, 2016. Disponível em:

$<$ http://g1.globo.com/economia/noticia/2016/10/cpfs-emitidos-junto-com-certidao-denascimento-superam-1-milhao.html>. Acesso em: 20 jun. 2017.

IBGE - INSTITUTO BRASILEIRO DE GEOGRAFIA E ESTATÍSTICA. Censo 2010: população do $\quad$ Brasil. $\quad$ Disponível $\quad$ em 17. $<$ http://www.ibge.gov.br/home/presidencia/noticias/noticia_visualiza.php?id_noticia=1766>. Acessado em 28 mar. 2018.

LÓPEZ, E; BOCCO, G; MENDOZA, M; DUHAU, E. Predicting land-cover and land-use change in the urban fringe. A case in Morelia city, Mexico. Landscape and Urban Planning, v. 55 , n.4, p. 271-285, 2001.

MAGALHÃES, Luís Felipe Aires. Fontes de dados demográficos e estudos de população em Santa Catarina. Revista NECAT-Revista do Núcleo de Estudos de Economia Catarinense, v. 4, n. 7, p. 23-37, 2015.

MAIA, Paulo Borlina; CARDOSO, Glauber Ferreira; DA SILVA, Daniel Waldvogel Tomé. Mortalidade por Agressão: um exercício com as informações do Atestado de Óbito georreferênciadas para município de São Paulo. Anais, p. 1-21, 2016.

MATUDA, Nivea da Silva. Introdução a demografia. Departamento de Estatística - UFPR. 2009.

NEGRI, Antonio. La fábrica de porcelana. Una nueva grámatica de la política. Traducción de Susana Lauro. Barcelona: Ediciones Paidós Ibérica, 2008.

NOGUEIRA, Ana Cláudia Fernandes; SANSON, Fábio; PESSOA, Karen. A expansão urbana e demográfica da cidade de Manaus e seus impactos ambientais. XIII Simpósio Brasileiro de Sensoriamento Remoto, Florianópolis, Brasil, v. 21, p. 26, 2007.

OJIMA, Ricardo. Território Mobilidade populacional e meio ambiente. Governador Valadares : UNIVALE, 2012. 
RAGO, Margareth. Figuras de Foucault. 2. Ed. Belo Horizonte: Autêntica, 2008.

SANTOS JUNIOR, O. A. dos; MONTANDON, D. T. (Org). Os planos diretores municipais pós estatuto da cidade: balanço crítico e perspectivas. Rio de Janeiro: Observatório das Cidades: IPPUR/UFRJ, 2011.

SANTOS, Reinaldo Velloso dos. Registro civil das pessoas naturais. Porto Alegre: Sergio Antonio Fabris, 2006.

SÃO PAULO. Provimento no 58/89 - Corregedoria Geral da Justiça. Normas de serviço cartórios extrajudiciais TOMO II. São Paulo 28 nov. 1989.

SEADE - FUNDAÇÃO SISTEMA ESTADUAL DE ANÁliSE DE DADOS. Dados de população. Disponível em: $<$ http://www.seade.gov.br/produtos/imp/index.p $>$. Acessado em 28 mar. 2018.

SIBILIA, Paula. O homem pós-orgânico: corpo, subjetividade e tecnologias digitais. São Paulo: Relume Dumara, 2002.

SILVA, José Borzacchiello da; LIMA, Luiz Cruz; CORREIA, Wanderley. Panorama da Geografia brasileira II. São Paulo: Annablume, 2006.

SOUZA, M. L. de. Mudar a cidade: uma introdução crítica ao planejamento e a gestão urbanos. 3. ed. Rio de Janeiro: Bertrand Brasil, 2004.

TUCCI, C. E. M. Gestão integrada das águas urbanas. Revista de Gestão de Águas da América Latina - REGA, v. 5, n. 2, p. 71-81, 2008. 